\title{
DOE/WIPP 93-043
}

\section{Effects of Salt Loading and Flow Blockage on the WIPP Shrouded Probe}<smiles>C1=C[C@H]2C=C[C@H](O1)O2</smiles>

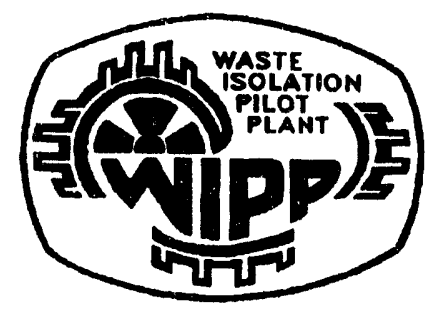

Waste Isolation Pilot Plant 
This document is issued by Westinghouse Electric Corporation, Waste Isolation Division, as the Management and Operating Contractor for the Department of Energy, Waste Isolation Pilot Plant, Carlsbad, New Mexico, 88221.

\title{
DOE CONTRACT NUMBER: DE-AC04-86AL31950
}

\section{DISCLAIMER}

This document was prepared as an account of work sponsored by an agency of the United States Government. Neither the United States Government nor any agency thereof, nor any of their employees, makes any warranty, express or implied, or assumes any legal liability or responsibility for the accuracy, completeness, or usefulness of any information, apparatus, product or process disclosed, or represents that its use would not infringe privately owned rights. References herein to any specific commercial product, process, or service by trade name, trademark, manufacturer, or otherwise, does not necessarily constitute or imply its endorsement, recommendation, or favoring by the United States Government or any agency thereof. The views and opinions of authors expressed herein do not necessarily state or reflect those of the United States Government or any agency thereof.

This document has been reproduced directly from the best possible copy. It is available to DOE and DOE contractors at the following address:

Office of Scientific and Technical Information

P. O. Box 62

Oak Ridge, TN 37831

Prices available from (615) 576-8401

\author{
Avallable to the public from the \\ National Technical Information Service \\ U. S. Department of Commerce \\ 5285 Port Royal Road \\ Springfield, VA 22161
}




\title{
Effects of Salt Loading and Flow Blockage on the WIPP Shrouded Probe
}

\author{
Prepared by: \\ Sumit Chandra \\ Carlos A. Ortiz \\ Andrew R. McFarland \\ Aerosol Technology Laboratory \\ Department of Mechanical Engineering \\ Texas A\&M University \\ College Station, TX 77843 \\ Submitted by: \\ Texas A\&M Research Foundation \\ P.O. Box 3578 \\ College Station, TX 77843
}

Submitted to:

Ms. Sheila Clayton

Westinghouse Electric Corporation

Waste Isolation Division

P.O. Box 2071

Carlsbad, NM 88221

Aerosol Technology Laboratory Report 8248A/01/08/93/SC

August 1993
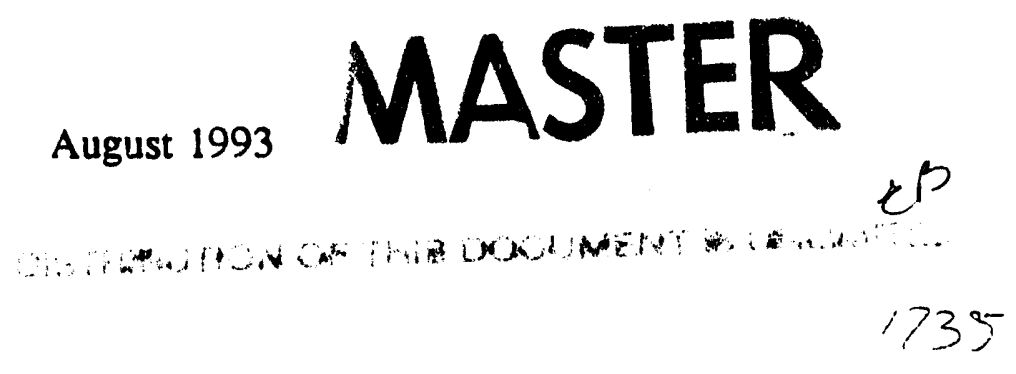


\section{EXECUTIVE SUMMARY}

The shrouded probes at the WIPP site operate in a salt aerosol environment that can cause a buildup of salt deposits on exposed surfaces of the probes that, in turn, could produce changes in the sampling performance of the probes. At Station A, three probes had been operated for a period of approximately $2 \frac{1}{2}$ years when they were inspected with a remote television camera. There were visible deposits of unknown thickness on the probes, so WIPP removed the probes for inspection and cleanup. Measurements were made on the probes and they showed the buildups to be approximately $2.5 \mathrm{~mm}$ thick on the most critical dimension of a shrouded probe, which is the inside diameter of the inner probe. For reference, the diameter of a clean probe is $30 \mathrm{~mm}$. The sampling performance of this particular shrouded probe had been previously evaluated in a wind tunnel at Aerosol Technology Laboratory (ATL) of Texas A\&M University for two free stream velocities (14 and $21 \mathrm{~m} / \mathrm{s})$ and three particie sizes $(5,10$ and $15 \mu \mathrm{m} \mathrm{AED})$.

A study was then conducted by the ATL to determine the effects of salt deposits on the aerosol sampling characteristics of shrouded probes. Sand, comprised of a range of particle sizes that simulate those observed in the salt deposits, was glued onto the regions ci a shrouded probe where the deposits were observed. The sand deposit buildup in the insice of the inner probe inlet was measured to be approximately $3 \mathrm{~mm}$ for this unit.

Sampling performance of the loaded shrouded probe relative to an identical clean shrouded probe was characterized through use of two aerosol wind turnels. Results, for $10 \mu \mathrm{m}$ AED aerosol particles, show the penetration ratio (transmission ratio of the loaded probe divided by the transmission ratio of the clean probe) varied from 0.79 at a free stream velocity of $2 \mathrm{~m} / \mathrm{s}$ to 0.72 at $21 \mathrm{~m} / \mathrm{s}$. The transmission ratio is the concentration of aerosol at the probe exit divided by the concentration of aerosol in the free stream.

The calculated transmission ratio of the salt-loaded unit at a free stream velocity of 14 $\mathrm{m} / \mathrm{s}$ and a particle size of $10 \mu \mathrm{m}$ AED would be 0.91 since the transmission ratio of the clean unit was previously determined to be 1.16 at those conditions. 
Two other WIPP shrouded probes were loaded with simulated salt deposits; one with a lighter loading (compared with that observed in the field) comprised of salt and dirt from the WIPP site and the second with a heavier loading of sand. The thicknesses of the deposits on the inside of the inner probes were approximately 1 and $6.5 \mathrm{~mm}$, respectively. The unit with the lighter loading exhibited a sampling performance much closer to that of the clean unit. It had a penetration ratio for $10 \mu \mathrm{m}$ AED aerosol particles that was approximately 0.90 for free stream velocities of 2 to $21 \mathrm{~m} / \mathrm{s}$. The shrouded probe with a heavier loading showed a penetration ratio that was approximately 0.50 for the same particle size and velocity range.

Experiments were conducted in which one-third of the waistline area between the shroud and the probe was blocked. This simulated a condition where a foreign object (cardboard) had inadvertently become lodged in that area during field sampling. A test at a free stream velocity of $14 \mathrm{~m} / \mathrm{s}$ and a particle size of $10 \mu \mathrm{m}$ AED with the simulated blockage showed the penetration ratio was 0.99 , which suggests there was no significant change in the sampling performance. Velocity profiles inside the shroud of the blocked unit and a clean unit were measured with a hot wire anemometer. At a location $51 \mathrm{~mm}$ downstream from the shroud inlet and $99 \mathrm{~mm}$ upstream from the probe inlet, both profiles are flat; however, the mean velocity with blockage is about $2 / 3$ that with no blockage.

Sharp-edged isokinetic probes were loaded with sand to simulate the effects of salt loadings that were observed on the shrouded probes at WIPP. A probe with a $13.4 \mathrm{~mm}$ diameter inlet that operates isokinetically at a flow rate of $6-\mathrm{cfm}$ in a free stream velocity of $21 \mathrm{~m} / \mathrm{s}$ and a flow rate of 4-cfm at a free stream velocity of $14 \mathrm{~m} / \mathrm{s}$ showed a penetration ratio (relative to a clean shrouded probe) of $40 \%$ for $10 \mu \mathrm{m}$ AED aerosol particles at a free stream velocity of $14 \mathrm{~m} / \mathrm{s}$. A second isokinetic probe with an inlet diameter of $6.4 \mathrm{~mm}$ that operates isokinetically at $1 \mathrm{cfm}$ at $14 \mathrm{~m} / \mathrm{s}$ showed a transmission ratio that was less than $20 \%$ relative to a clean isokinetic probe.

A numerical model of the performance of a shrouded probe was used to confirm the experimental results. For a shroucled probe loaded similar to that observed in the field and operated at $6 \mathrm{cfm}$ in a $14 \mathrm{~m} / \mathrm{s}$ flow, the maximum deviation in penetration ratio between computation and experiment was $10 \%$. 


\section{INTRODUCTION}

Continuous monitoring of effluent ventilation air is used at the WIPP site for detection in case there should be a release of radioactivity in the underground mine area. There are two above-ground stations where aerosol is sampled from the ventilation ducts. Station $A$ is located in a main 14-ft diameter ventilation shaft that has a range of design flow rates from 60,000 to $420,000 \mathrm{cfm}$ with flows to $650,000 \mathrm{cfm}$ possible. Under normal operation the flow rate is $420,000 \mathrm{cfm}$ and if radioactivity were detected, the flow rate would be reduced to $60,000 \mathrm{cfm}$. Also, the main flow is induced by two above-ground induced-draft fans. If one of the fans was not operated, the flow rate would be approximately $210,000 \mathrm{cfm}$. The sampling probes at Station A are potentially subjected to a range of free stream velocities of 2 to $21 \mathrm{~m} / \mathrm{s}$.

The second above-ground sampling station, called Station B would be used only if there were an indication of radioactivity in the mine ventilation air. Under such a situation, the flow rate in the main ventilation shaft would be reduced to $60,000 \mathrm{cfm}$. A.l of the ventilation air would be passed through HEPA filters and then discharged to the environment through an exhaust duct. Station B is located in the exhaust duct that leads from the HEPA filters.

The WIPP storage area is located 2150 -ft below grade in bedded salt. Because of mining and operational activities, there is a background aerosol in the ventilation exhaust air that is comprised of salt, dirt and diesel fume. The concentration averages $0.04 \mathrm{mg} / \mathrm{m}^{3}$ but it can be as high as $5 \mathrm{mg} / \mathrm{m}^{3}$. Some of this aerosol is deposited on the sampling probes at Station A and because the probes are operated continuously, the deposits can build up. There is little opportunity for deposition on the Station B probes since they are not normally exposed to the salt aerosol. Such exposure only occurs during periods when there is maintenance on both $210,000 \mathrm{cfm}$ fans and the mine ventilation air is induced by fans at the entrance of the Station B ducting. Under such a circumstance, the ventilation air flow bypasses the HEPA filters.

Partly because of the potential for salt buildup on multiple sampling probes, the WIPP facility chose to use single point representative sampling with shrouded probes rather than multiple probes. Under the guidance of AN:I N13.1 (1969), which was the standard in effect 
at the time the probes were installed, the recommended minimum number of probes was six. However, the ANSI standard permits fewer probes to be used if it can be shown the velocity and concentration profiles are well developed. Since there are approximately 150 diameters of straight pipe ahead of Station A, and approximately 50 diameters are needed for assurance of adequate mixing (Hampl et al., 1987), the number of probes was reduced to one. The flow rate through the sampling system at WIPP is 6-cfm and, had six probes been employed, the probe diameter for isokinetic operation at the $14 \mathrm{~m} / \mathrm{s}$ velocity would have been $6.6 \mathrm{~mm}$; whereas, with the single-point shrouded probe, the diameter of the internal probe is $30 \mathrm{~mm}$. This difference in diameter would have a significant effect upon the response of a probe to salt loading.

The WIPP shrouded probes (Figure 1) were developed in the Aerosol Technology Laboratory (ATL) of Texas A\&M University (McFarland et al., 1989). Laboratory tests were conducted on the shrouded probe over a range of particle sizes from 1 to $15 \mu \mathrm{m}$ aerodynamic equivalent diameter (AED) and a range of free stream velocities of 2 to $14 \mathrm{~m} / \mathrm{s}$. Recently, further laboratory tests were carried out for the free stream velocity of $21 \mathrm{~m} / \mathrm{s}$. Chandra et al. (1993) tested the shrouded probe under those conditions.

The WIPP probes have been in operation since 1989. Periodically, a television camera is lowered into the 14-ft diameter main ventilation shaft to check the integrity of the shaft and, during a recent test, it was noted there were salt deposits on the exterior regions of all three shrouded probes at the Station A location. It had been 29 months since the probes were last cleaned when they were removed for inspection and cleaning in April 1993. A representative of ATL was present when the probes were removed and he made measurements of the salt at critical locations on the probes. The salt thickness averaged approximately $2.5 \mathrm{~mm}$ in the location that could most adversely affect the sampling performance of the shrouded probe, i.e., on the inside surface of the inner probe inlet. It was noted that in one shrouded probe, a piece of cardboard had become lodged in the waistline between the probe and shroud. It blocked about $1 / 3$ of the flow passage in that region. 


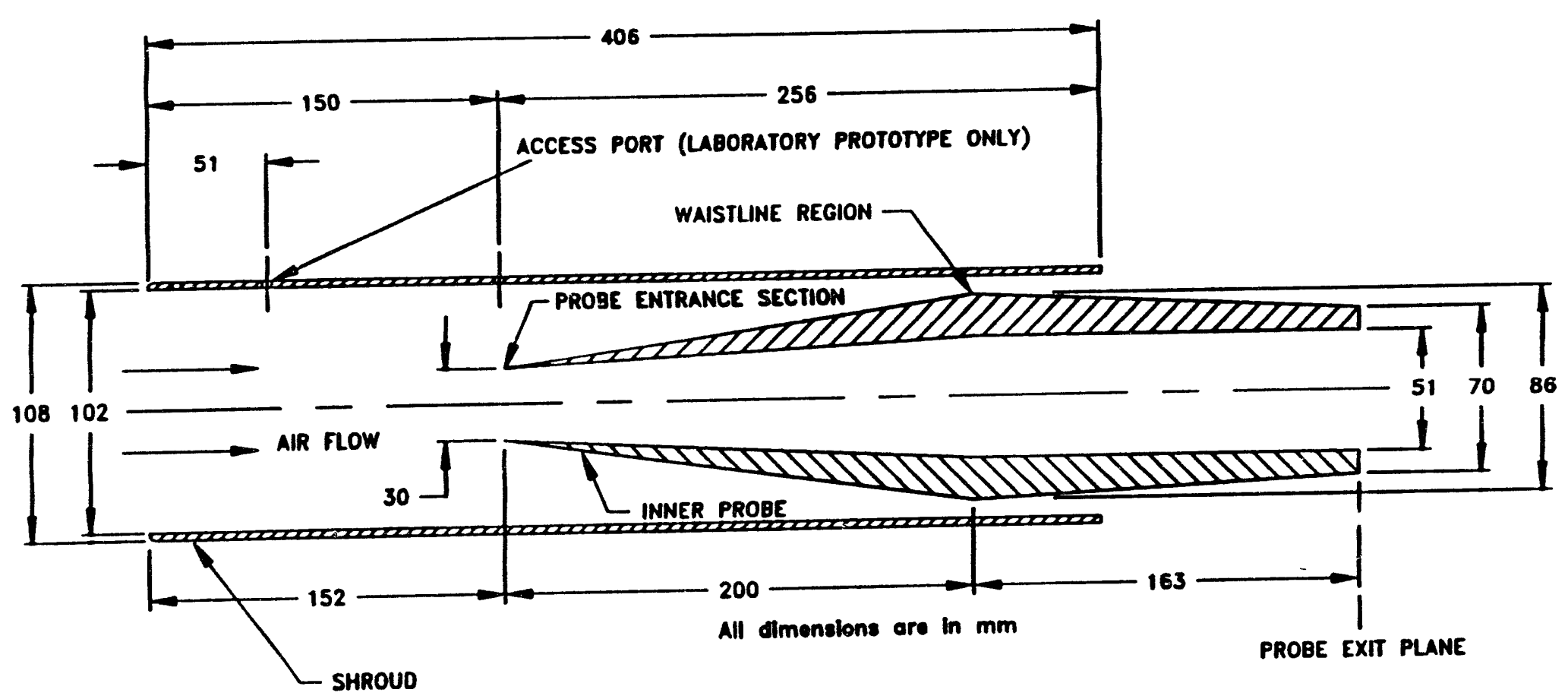

Figure 1. WIPP shrouded probe. Sampling flow rate is $6 \mathrm{cfm}$. 
In this study, we investigated with wind tunnels the effects upon the aerosol sampling characteristics of simulated salt buildup on the surfaces of the shrouded probe and isokinetic probes. We also simulated the effect of flow blockage caused by a foreign object lodged in the region between the shroud and probe. A numerical model (Gong et al., 1993) was used to predict the effects of salt loading and flow blockage in order to verify selected experimental results.

The buildup of salt will alter the dimensions of the shrouded probe and also roughen the inside surfaces of both the shroud and the probe. Salt buildup reduces the inlet area of the probe and the waistline area between the probe shoulder and shroud. Reduction of inlet area of the probe increases the velocity at the inner probe inlet for a given sampling flow rate. This will cause a reduction in particle concentration in the sampled aerosol due to an anisokinetic effect. A reduction in the waistline area will accentuate flow deceleration inside the shroud. That could cause an increase in the aerosol concentration in the shroud and partially offset the effect of salt buildup on the inner probe. The added reality of a rough surface inside the probe tends to increase the wall loss of aerosol particles; thereby, further degrading the net aerosol transmission. However, as the effective sampling process for a shrouded probe takes place inside the shroud where the free stream velocity is reduced to approximately 0.4 of the free stream velocity, the particle Stokes numbers are much lower compared with an equivalent sampling situation employing isokinetic probes. Such low Stokes numbers ensure that the negative bias mechanism caused by reductions in critical areas, is dampened in comparison with the effects that would be produced in small diameter isokinetic probes. For the isokinetic probes, the probe inlet velocity is so much higher that a reduction in area, coupled with a rough surface inside the probe, produces a much worse sampling performance.

\section{METHODOLOGY}

\section{Testing with Aerosol Wind Tunnels.}

The layout of the aerosol wind tunnels that were used for the experiments are shown in Figures 2 and 3 . The wind tunnel arrangement of Figure 2 covered the free stream velocity 
un

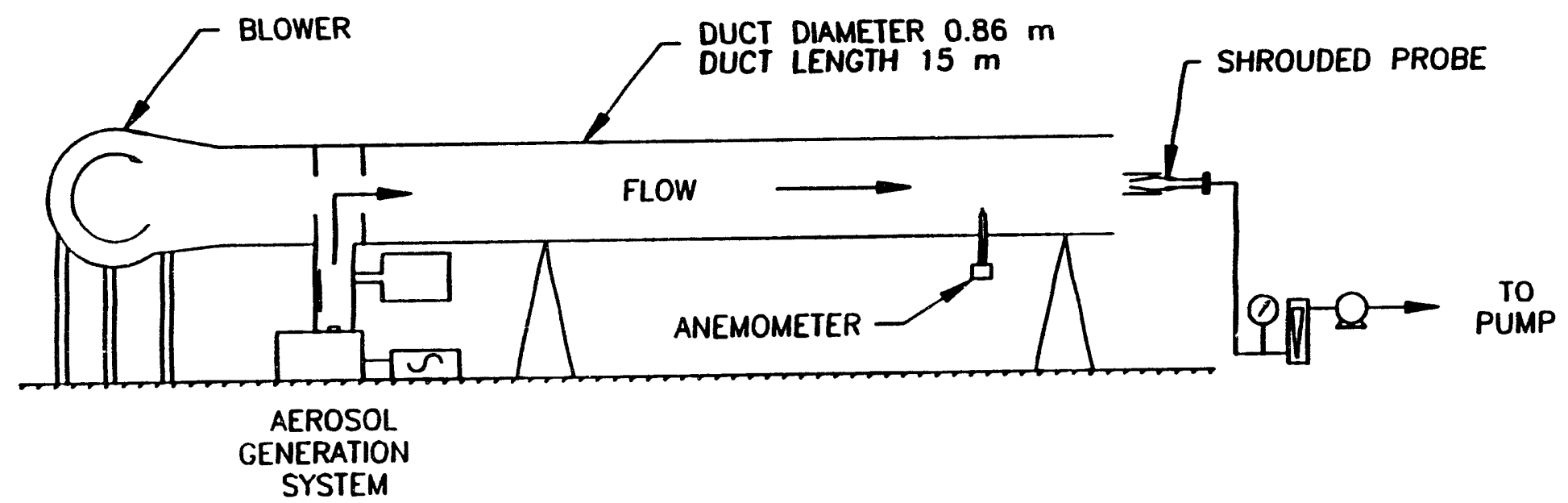

Figure 2. Aerosol wind tunnel used for tests at wind speeds of $4-21 \mathrm{~m} / \mathrm{s}$. 


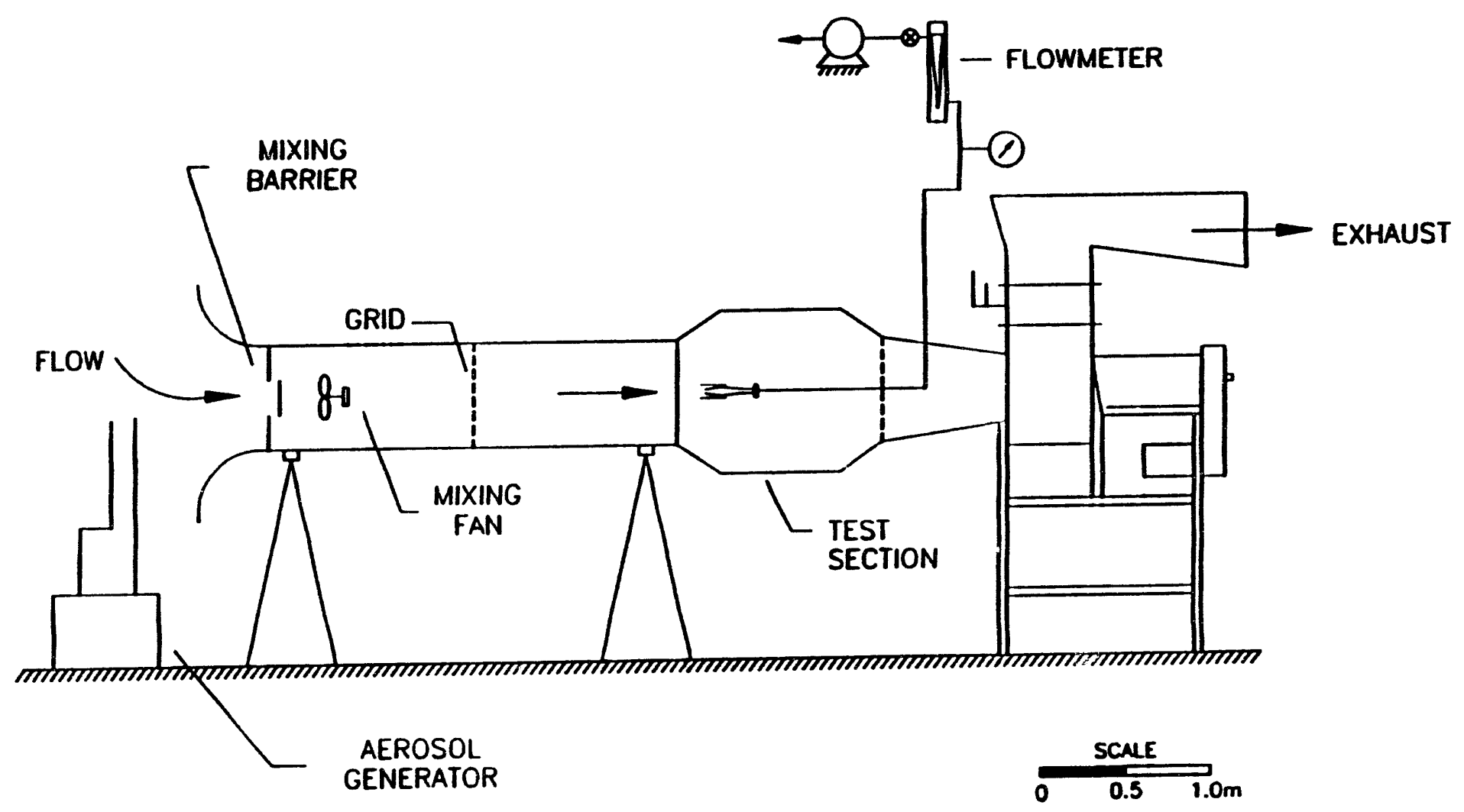

Figure 3. Wind tunnel used for tests at a wind speed of $2 \mathrm{~m} / \mathrm{s}$. 
range of 4 to $21 \mathrm{~m} / \mathrm{s}$ while that shown in Figure 3 was used for tests at a free stream velocity of $2 \mathrm{~m} / \mathrm{s}$.

Monodisperse aerosol was introduced into the upstream region of a wind tunnel, where it was mixed into the main air flow either by induced turbulence in the tunnel (arrangement as in Figure 2) or by additional with a mixing fan (arrangement as in Figure 3), and sampled at the test section with a probe. The aerosol transmission ratio, $T$, through a test probe is defined as:

$$
T=\frac{c_{p}}{c_{\infty}}
$$

where: $c_{p}=$ aerosol concentration at the exit plane of a test probe and $c_{\infty}=$ aerosol concentration in the free stream of the wind tunnel. For this study, it was not the actual value of aerosol transmission ratio that was measured, but rather the relative transmission ratio of a loaded probe (i.e., one coated with simulated salt) to the transmission ratio of a clean probe. To quantify the performance of the loaded probes of this study, we have used a new parameter, the penetration ratio, $P_{r}$, which is defined as:

$$
P_{r}=\frac{T_{p p}}{T_{c p}}=\frac{c_{p p}}{c_{c p}}
$$

where: $T_{t p}$ is the transmission ratio for the test probe; $T_{c p}$ is the transmission ratio of a clean probe; $c_{t p}$ is the aerosol concentration at the exit plane of the test probe; and, $c_{c p}$ is the aerosol concentration at the exit plane of a clean probe. The value of $P_{r}$ was determined from the aerosol collected on filters placed at the exit planes of the clean and loaded probes.

Aerosol droplets were generated with a vibrating jet atomizer (Berglund and Liu, 1973) from a solution of oleic acid in alcohol. An analytic tracer, sodium fluorescein, was added to the solution in a ratio of 1:10 (mass/volume). Upon evaporation of the alcohol, stable residual droplets of oleic acid tagged with the tracer remained and served as the actual test aerosol. The residual particle size produced by the generator was measured microscopically by first collecting the droplets on a glass slide that had an oil phobic coating. Gravitational flattening of the droplets was taken into account through the use of the factor of Olan-Figueroa et al. (1982).

In conducting an aerosol test, the desired free stream velocity was first established, the aerosol generator system was started and the correct particle size was obtained. Then a test probe was placed in the test section. After the probe had been exposed to the aerosol for a time 
sufficient to collect an easily analyzable amount of tracer, additional probes were sequentially placed in the test section and operated an identical length of time. Flow through the probes was monitored with calibrated rotameters. Readings were adjusted to take into account the pressure differential between calibration and test conditions. The shrouded probes were operated at a flow rate of $6 \mathrm{~cm}$. At the completion of the wind tunnel exposure, filters used to collect aerosol transmitted through the probes were removed and placed into solutions of isopropyl alcohol and water to elute the fluorescent tracer. The amount of fluorescent tracer in the solution was quantified with a fluorometer (Model 450, Sequoia-Turner Corp., Mountain View, CA).

The testing procedure for free stream velocities of 14 and $21 \mathrm{~m} / \mathrm{s}$ was to sequentially test either 2, 3 or 4 probes, of which one probe was a clean unit and the remainder was units loaded with salt or sand, or having blockage. For test conditions at a free stream velocity of $2 \mathrm{~m} / \mathrm{s}$, the same procedure was followed.

Three to six replicate tests were run at each experimental condition. Data points for ninety percent of the experimental conditions had four or more replicates.

Two clean probes were used in the aerosol testing - one was a spare prototype obtained from WIPP and the second was a laboratory prototype. The only differences between the two probes were that: (1) access ports had been machined into the shroud of the laboratory prototype for insertion of a hotwire anemometer probe into the region between the shroud inlet plane and inner probe inlet plane, and, (2) mounting screws were used to hold the probe inside the laboratory prototype while struts served that function with the WIPP prototype. During aerosol tests, the access ports of the laboratory prototype were sealed to obtain aerodynamic surface conditions in the shroud that were identical to those in the WIPP probe. Tests were conducted at a free stream velocity of $14 \mathrm{~m} / \mathrm{s}$ with $10 \mu \mathrm{m}$ AED particles and also at $2 \mathrm{~m} / \mathrm{s}$ with 5, 10 and $15 \mu \mathrm{m}$ AED particles to compare sampling characteristics of the two prototypes. Aerosol transmitted through the two probes was within $\pm 3 \%$ for all tests. These results show that the two probes could be used interchangeably as the clean probe of any test.

\section{Measurement of Velocities in the Shrouds.}

Velocity profiles inside the shroud were obtained for a shrouded probe with no blockage and for a probe fitted with non-symmetrical blockage. The blockage arrangement is shown in Figure 4. This configuration resulted in blocking approximately $33 \%$ of the area between the 


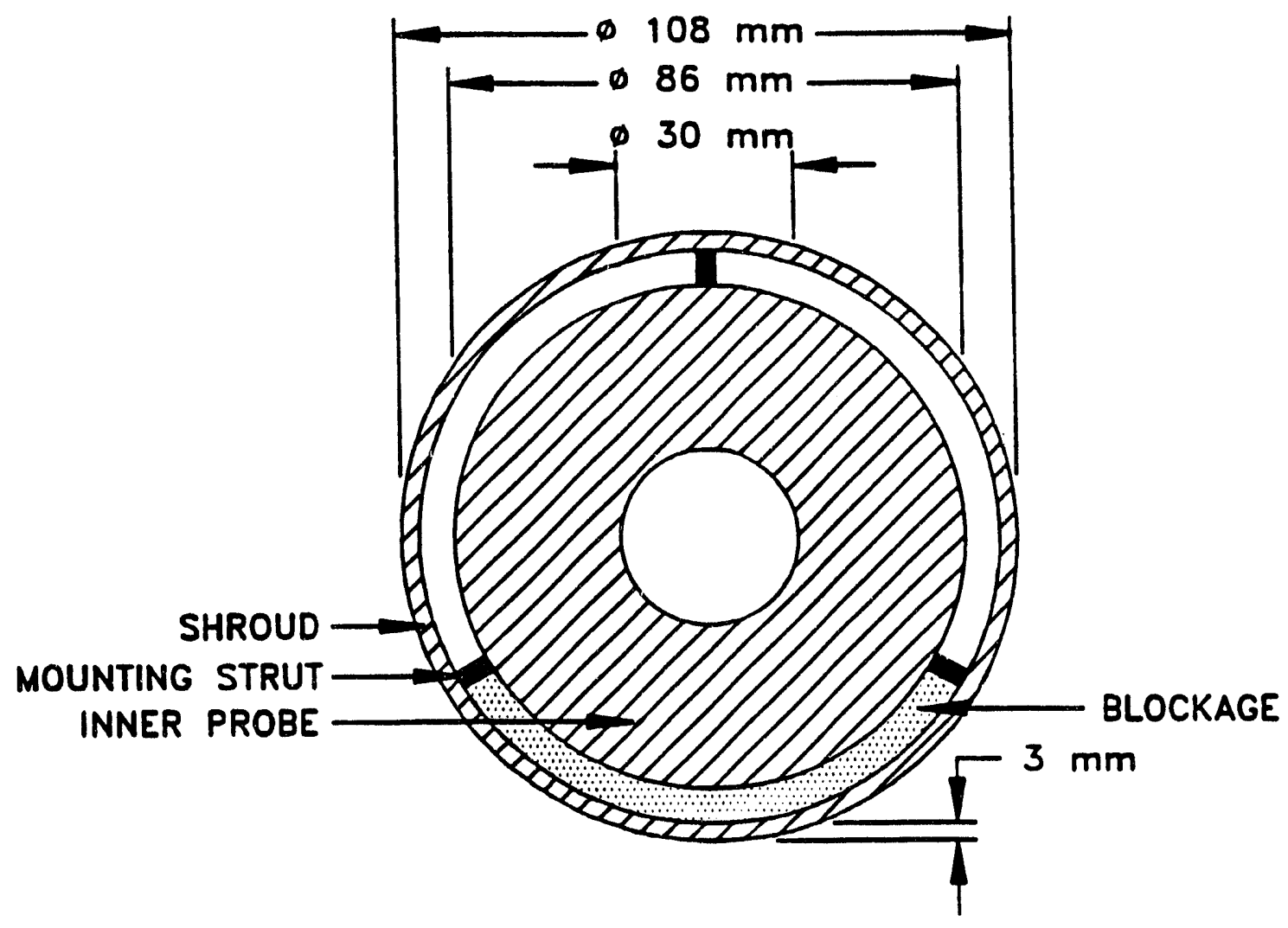

Figure 4. Blockage placed between shroud and probe. One-third of the flow area in the waistline region was blocked. 
probe waist and the shroud. The velocity profiles were established by inserting a hot wire anemometer probe through the access port in the shroud and taking readings at various distances across the shroud diameter. The port was located $51 \mathrm{~mm}$ from the shroud entrance and $99 \mathrm{~mm}$ upstream of the inner probe entrance. A Model IFA 100/200 (TSI Inc., St. Paul, MN) hot wire anemometer was used for the tests.

\section{Simulated Salt Buildup on Surfaces of the Shrouded Probes.}

Buildup of particulate matter on the probes was achieved by attaching either sand or salt on the probe surfaces with an adhesive. For the sand layer, we first used a coarse sand (a 16/30 sieve fraction, i.e. the sand grains passed through a 16 mesh per inch sieve and were retained on a 30 mesh per inch sieve). These sand particles had an effective size of approximately 450 $\mu \mathrm{m}$. Then a second layer of finer sand particles (a 30/80 sieve fraction with an effective size of $220 \mu \mathrm{m}$ ) was applied with adhesive. In using salt/dirt mixture for the buildup material, a similar procedure was employed. The salt and dirt material was obtained from the WIPP site. The effective sizes of coarse sait/dirt (a 16/30 sieve fraction) and of fine salt/dirt (a 30/80 sieve fraction) were approximately $220 \mu \mathrm{m}$ and $180 \mu \mathrm{m}$, respectively.

Three probes were loaded with sand or the mixture of salt and dirt from WIPP. Photographs of the probes are shown in Figure 5. The first probe, which shall be referred to as SPRA (Figure 5b), was loaded with sand in a manner that was intended to mimic the average salt deposits observed in the field on the units removed from WIPP Station A. The dimensions of the sand deposits are summarized in Table 1, where the thicknesses of deposits may be determined by comparing dimensions with those of the clean probe. For example, the difference between the outside and inside diameters of the shroud inlet of a clean probe is $6.4 \mathrm{~mm}$ whereas the difference of those dimensions for SPRA is about $20 \mathrm{~mm}$. The sand thickness on the iniet of the shroud of SPRA was thus approximately $3.4 \mathrm{~mm}$. The thickness of the sand deposits on the inside of the inner sampling probe was approximately $3 \mathrm{~mm}$. whereas the diameter of a clean inner probe inlet is $30 \mathrm{~mm}$.

The second probe (SPRB) had a sand buildup that was heavier than that observed on the probes in the field, Figure 5c. As may be noted from Table 1, the buildup on the inside surface of the inner probe was approximately $6.5 \mathrm{~mm}$. One of the shrouded probes removed from Stati- 


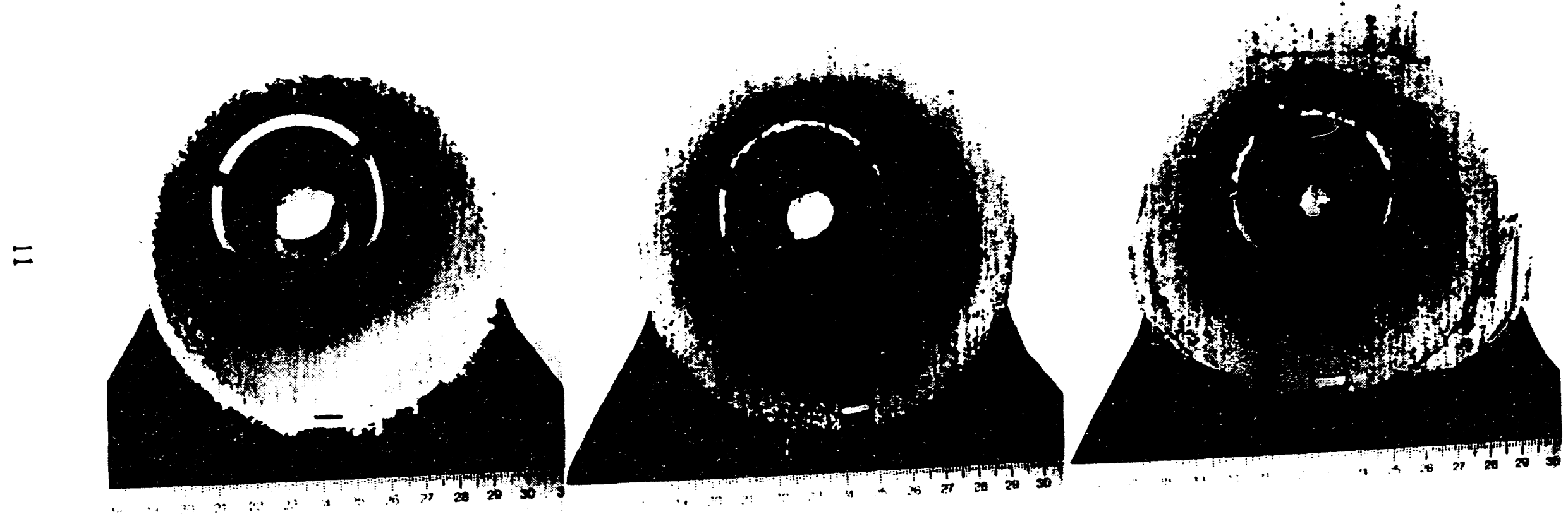
a) Deposits lighter than field, SPRC.
b) Deposits similar io field, SPRA.

c) Deposits heavier than field, SPRB.

Figure 5. Photographs of deposits on shrouded probes. View is from front of the shroud. Scale is in units of centimeters. Deposits have been removed at the $60^{\prime}$ clock position. 
Table 1. Nomenciature and dimensions $(\mathrm{mm})$ of the different probes.

\begin{tabular}{|c|c|c|c|c|c|c|c|}
\hline \multirow[b]{2}{*}{$\begin{array}{l}\text { Probe } \\
\text { Description }\end{array}$} & \multirow[b]{2}{*}{ Name } & \multicolumn{2}{|c|}{ Shroud Inlet } & \multicolumn{2}{|c|}{ Probe Inlet } & \multirow[b]{2}{*}{$\begin{array}{l}\text { Waistline } \\
\text { Gap }\end{array}$} & \multirow{2}{*}{$\begin{array}{l}\text { I.D. of } \\
\text { Probe } \\
\text { Outlet }\end{array}$} \\
\hline & & O.D. & I.D. & O.D. & I.D. & & \\
\hline $\begin{array}{l}\text { Clean Shrouded } \\
\text { Probe (Fig. 1) }\end{array}$ & Clean & 108 & 101.6 & 30.0 & 30.0 & 8.2 & 52.1 \\
\hline $\begin{array}{l}\text { Shrouded Probes } \\
\text { as } \\
\text { Observed in } \\
\text { Field }\end{array}$ & & 112 & 97 & 36 & 25 & 7.6 & 48 \\
\hline $\begin{array}{l}\text { Shrouded Probe } \\
\text { Loaded Similar } \\
\text { to Field (Fig. } \\
\text { 5b) }\end{array}$ & SPRA & 116 & 96 & 38 & 24 & 6.4 & 51 \\
\hline $\begin{array}{l}\text { Shrouded Probe } \\
\text { Loaded Heavier } \\
\text { than Field } \\
\text { (Fig. 5c) }\end{array}$ & SPRB & 116 & 90 & 46 & 17 & 5.8 & 44 \\
\hline $\begin{array}{l}\text { Shrouded Probe } \\
\text { Loaded Lighter } \\
\text { than Field } \\
\text { (Fig. 5a) }\end{array}$ & SPRC & 110 & 98 & 35 & 28 & 7.9 & 52 \\
\hline $\begin{array}{l}\text { Clean Isokinetic } \\
\text { Probe (Fig. 6a) }\end{array}$ & & & & 13.4 & 13.4 & & \\
\hline $\begin{array}{l}\text { Small Clean } \\
\text { Isokinetic Probe }\end{array}$ & & & & 6.4 & 6.4 & & \\
\hline $\begin{array}{l}\text { Small Loaded } \\
\text { Isokinetic Probe }\end{array}$ & IKPA & & & 9.3 & 4.6 & & \\
\hline $\begin{array}{l}\text { Loaded } \\
\text { isokinetic probe }\end{array}$ & IKPB & & & 19 & 8 & & \\
\hline
\end{tabular}


on A at WIPP had an irregular sait buildup on the shroud inlet. Sand loading on the inlet of the shroud of SPRB was formed in a similar irregular shape.

Buildup on the third probe, SPRC, consisted of the salt/dirt mixture from WIPP with the level of loading lighter than that observed in the field, Figure 5a. The thickness of salt on the inside of the inner probe was approximately $1 \mathrm{~mm}$ (Table 1 ).

Although the most critical dimension from the standpoint of sampling is the inside diameter of the inner probe, the waistline gap is also of concern. As the gap is reduced due to loading, the flow through the shroud is reduced. For a clean probe, the waistline gap is $\mathbf{8 . 2}$ $\mathrm{mm}$; whereas those for the lightly loaded, "similar-to-field" loaded and heavily loaded shrouded probes were 7.9, 6.4 and $5.8 \mathrm{~mm}$, respectively. The gaps measured in the field units averaged $7.6 \mathrm{~mm}$.

Photographs of a clean isokinetic probe and an isokinetic probe loaded with sand are shown in Figures $6 \mathrm{a}$ and $6 \mathrm{~b}$, respectively. The inlet diameter of the clean probe is $13.4 \mathrm{~mm}$ and the thickness of sand in the inside of the loaded probe is approximately $2.7 \mathrm{~mm}$ - about the same value as noted on the inside of the inner probe in the field units. This sand-loaded isokinetic probe is referred to as IKPB.

The small isokinetic probes were straight sharp-edged tubes that were $200 \mathrm{~mm}$ long. The inlet diameter of the clean probe was $6.4 \mathrm{~mm}$ and the thickness of sand inside the loaded probe was approximately $1.8 \mathrm{~mm}$. Deposits extended to approximately $30 \mathrm{~mm}$ from the entrance of the probe. The sand loaded probe is referred to as IKPA.

\section{Numerical Modeling.}

Gong et al. (1993) developed a numerical model to predict the transmission ratios of shrouded probes. Essentially the model uses finite element computational fluid dynamics software to model the fluid flow and a particle tracking technique to determine whether particles are deposited on the walls of the probe or if they are transmitted through the probe. Simulated salt deposits were accommodated into the model by changing the diameter of the shroud and inner probe inlets. Blockage was taken into account by modifying the inlet geometries of the shroud anc' nner probe. 


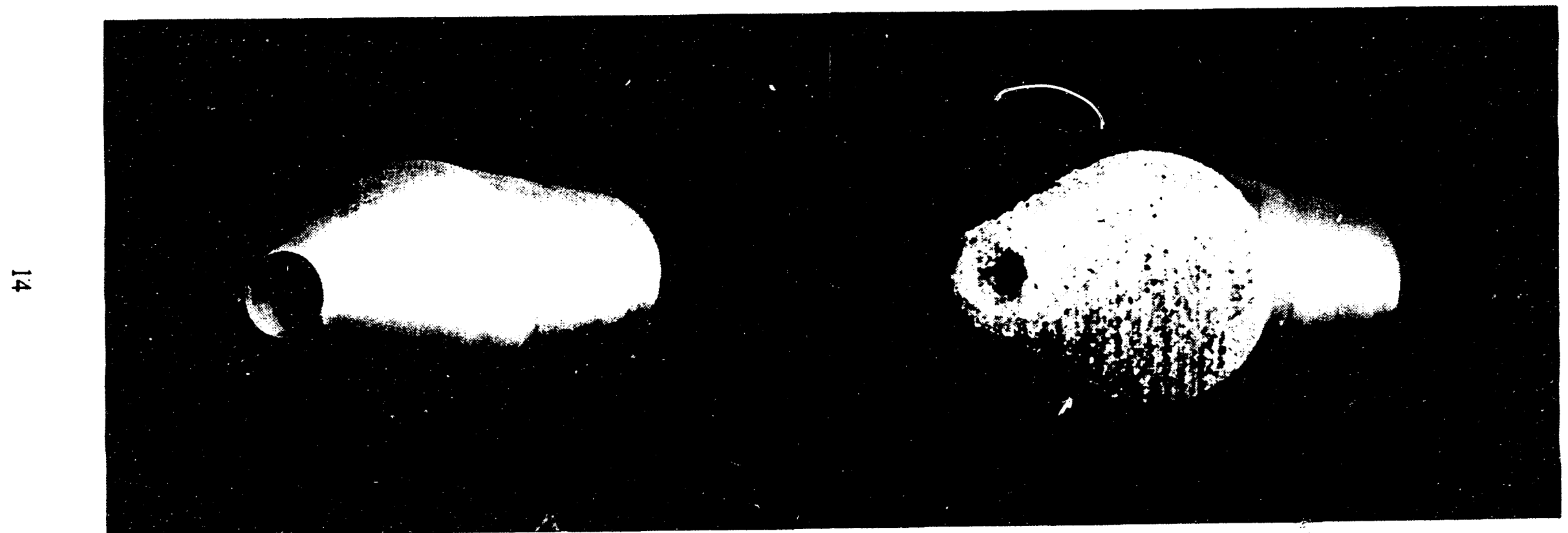

Figure 6. Isokinetic probe. a) Clean. b) With sand deposits. The inside diameter of the inlet of the clean probe is $13.4 \mathrm{~mm}$ and that of the loaded probe is approximately $8 \mathrm{~mm}$. 


\section{RESULTS ANU DíSCUSSION}

\section{Simulated-Salt Loadings on Shrouded Probes.}

Shown in Figure 7 is the penetration ratio, $P_{r}$, for SPRA (the probe loaded with sand deposits that simulate those observed in the field) for a range of free stream velocities and particle sizes. For $10 \mu \mathrm{m}$ AED particles, the penetration ratio is 0.79 at a free stream velocity of $2 \mathrm{~m} / \mathrm{s}, 0.78$ at $14 \mathrm{~m} / \mathrm{s}$ and 0.72 at $21 \mathrm{~m} / \mathrm{s}$. We believe the reduction in $P_{r}$ below the value of unity of a clean probe is primarily due to the fact the inlet area of the inner probe is only $63 \%$ of the original area. The waistline gap is $73 \%$ that of the clean shrouded probe but that effect is not believed to be consequential. The sampling efficiency is also reduced as a result of increased particle losses on the rough surface inside the inner probe.

The effects of the simulated salt loading are of the same order fur the entire free stream velocity range - the penetration ratio for $10 \mu \mathrm{m}$ AED particles varies only from 0.72 to 0.79 for free stream velocities from 2 to $21 \mathrm{~m} / \mathrm{s}$.

As would be expected, there is a decrease in the penetration ratio with increasing particle size at a given free stream velocity. For example, at $14 \mathrm{~m} / \mathrm{s}$ the penetration ratio is 0.87 for 5 $\mu \mathrm{m}$ AED particles and it is 0.71 for the $15 \mu \mathrm{m}$ size. This is because the effects of both reduced inner probe inlet area and surface roughness are inertially dominated, and aerosol particle inertia increases with increasing particle size.

It should be noted that the values used for plotting the graphs are penetration ratios and not transmission ratios, where the latter is the particle concentration at the exit of the probe to the free stream concentration.

The sampling characteristics of the different simulated salt loaded probes are given in Figure 8 where data are presented for SPRA, SPRB, SPRC and IKPB. All tests were conducted with $10 \mu \mathrm{m}$ AED aerosol particles. Flow rates through all the shrouded probes were set at 6$\mathrm{cfm}$ for all conditions. On the other hand, to maintain isokinetic conditions, IKPB was operated at a flow rate of $6-\mathrm{cfm}$ at a free stream velocity of $21 \mathrm{~m} / \mathrm{s}$ and a flow rate of 4-cfm at the $14 \mathrm{~m} / \mathrm{s}$ test speed. When examining Figure 8, it should be noted that the effects of loading are the result of three factors, namely: 1) changes in aspiration of the inner probe inlet due to changes in free stream velocity; 2) changes in wall losses inside the inner probe with changes in free 


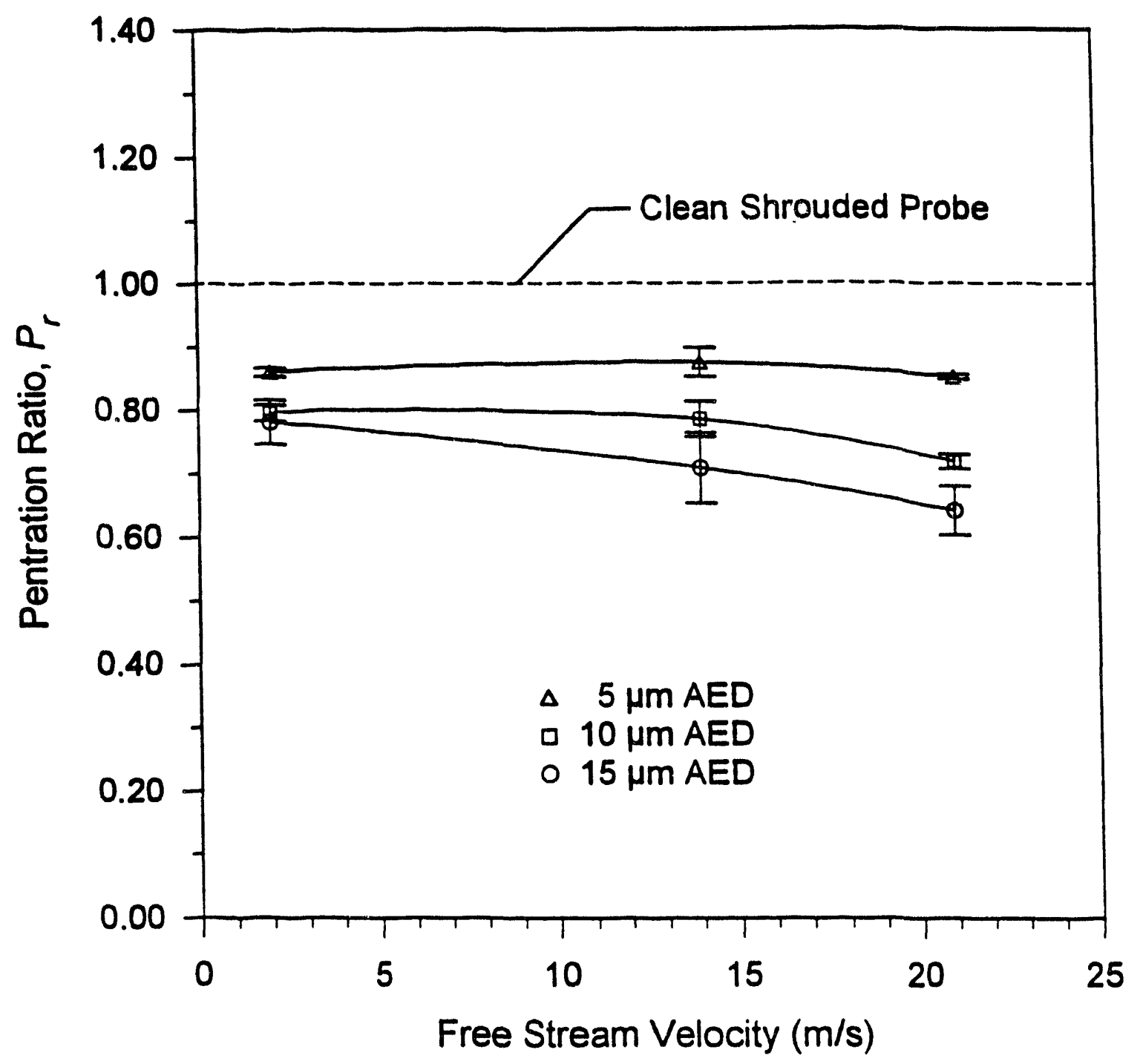

Figure 7. Penetration ratio of SPRA (similar buildup to that noted in the field) as a function of wind speed and particle size. Error bands represent \pm one standard deviation. 


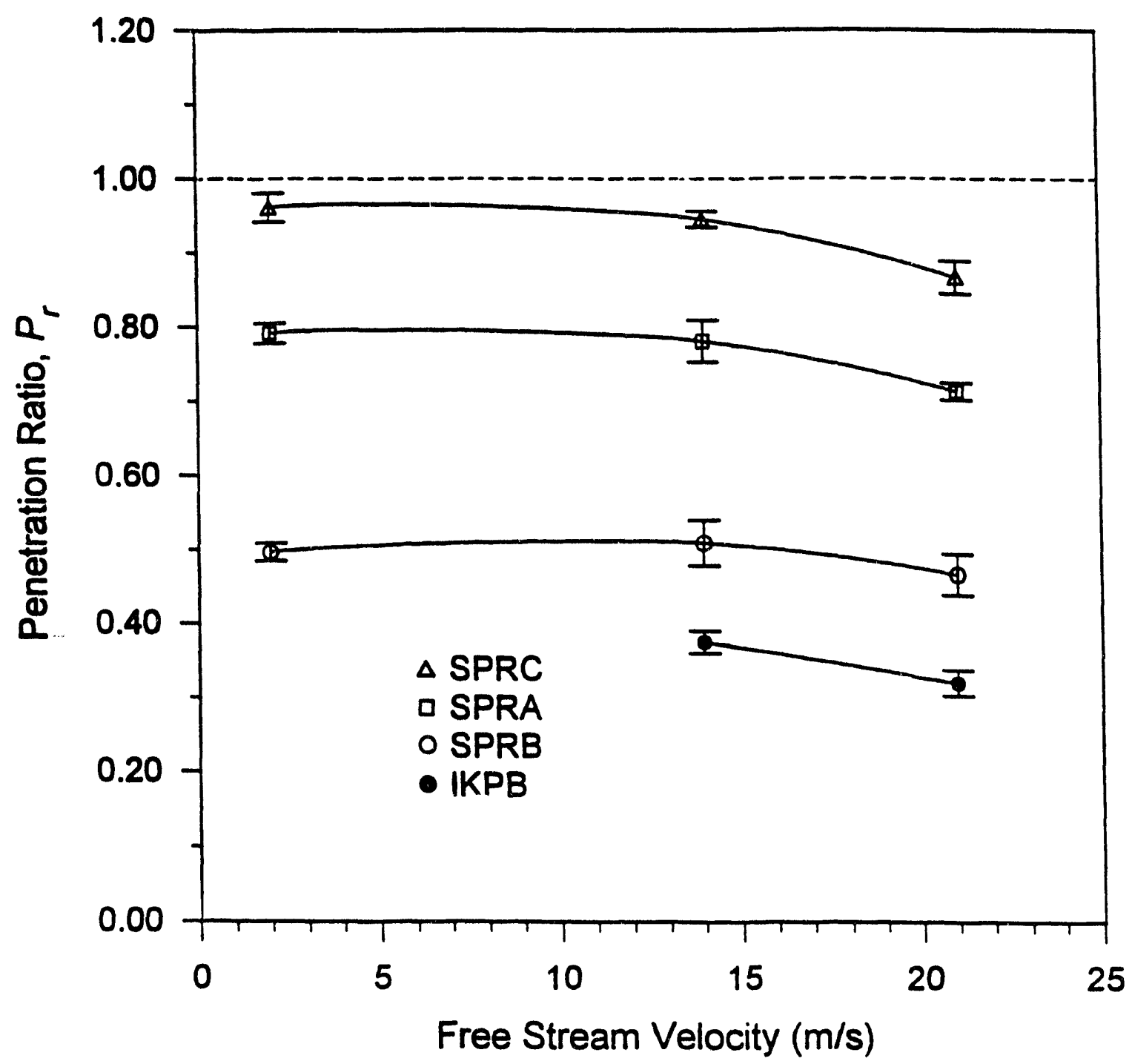

Figure 8. Penetration ratio of loaded probes as a function of free stream velocity. Particle size $=10 \mu \mathrm{m} \mathrm{AED}$. Error bands represent \pm one standard deviation. 
stream velocity; and, 3) changes in aspiration at the inner probe inlet due to change in buildup of particulate at the probe inlet.

For the lightest simulated-salt loading, SPRC, the penetration ratios for different free stream velocities are closer to unity than those for other shrouded probe loadings. At $2 \mathrm{~m} / \mathrm{s}$, the penetration ratio is 0.96 . At $14 \mathrm{~m} / \mathrm{s}$ the effects of increased wall losses and aspiration, as compared with a velocity of $2 \mathrm{~m} / \mathrm{s}$, appear to offset each other and the penetration ratio remains almost the same at 0.95 . However, at the free stream velocity of $21 \mathrm{~m} / \mathrm{s}$ the effect of an increase in wall losses is more pronounced than the effect of increased aspiration and the penetration ratio drops to 0.87 . Similar trends are noted for the probe that was loaded at approximately the same level at those observed in the field (SPRA). The penetration ratios for the free stream velocities of 2,14 and $21 \mathrm{~m} / \mathrm{s}$ are $0.79,0.78$ and 0.72 respectively. For SPRB, which has the heaviest buildup, the values of penetration ratios are 0.50 and 0.51 respectively at 2 and $14 \mathrm{~m} / \mathrm{s}$. At $21 \mathrm{~m} / \mathrm{s}$ the effect of increased wall losses is greater than the effect of increased aspiration (compared to the clean probe) and the penetration ratio drops to 0.47 .

The performance of shrouded probe SPRB is important from the standpoint that it shows the loading that causes a deterioration in performance of sampling $10 \mu \mathrm{m}$ AED particles to a level that is approximately $1 / 2$ that of the clean probe. The inside diameter of the inner probe was $17 \mathrm{~mm}$ as compared with the $30 \mathrm{~mm}$ diameter of a clean inner probe.

\section{Simulated Salt Loadings on Isokinetic Probes.}

Isokinetic probe IKPB has an inlet diameter of $13.4 \mathrm{~mm}$ and it was coated with sand (Figure 6) such that the inside diameter of the inlet was changed to an average value of approximately $8 \mathrm{~mm}$. This provided a sand layer thickness of $2.7 \mathrm{~mm}$ on the inside surface of . the probe inlet. By comparison, the inlet diameter of the inner probe for SPRA was measured to be $24 \mathrm{~mm}$ compared with a clean probe diameter of $30 \mathrm{~mm}$, which provided a sand layer of $3 \mathrm{~mm}$ thickness. The isokinetic probe was designed to have a flow rate of 6-cfm at a free stream velocity of $21 \mathrm{~m} / \mathrm{s}$ while the shrouded probe has a flow rate of $6-\mathrm{cfm}$ at all velocities. Because of the similarity of sand loading and the flow rates, the performance of these two units provides a direct comparison of the susceptibility of the shrouded and unshrouded probes to the effects of deposits of particulate matter on the critical surfaces. 
The penetration ratio for the sand-loaded isokinetic probe, IKPB, as compared with a clean shrouded probe is 0.38 at $14 \mathrm{~m} / \mathrm{s}$ and 0.32 at $21 \mathrm{~m} / \mathrm{s}$ for $10 \mu \mathrm{m}$ particles. Equivalent figures for SPRA were 0.78 and 0.72 , respectively. Thus, the loaded unshrouded probe only collects about $1 / 2$ of the $10 \mu \mathrm{m}$ AED aerosol particles of an equivalently loaded shrouded probe.

If the ANSI-recommended practice of using a multiple probe rake had bec imployed at WIPP Station A, at least 6 probes each operating at $1 \mathrm{cfm}$ would have been required. The diameters of these probes would be approximately $6 \mathrm{~mm}$, which is considerably smaller than that of the single 6-cfm isokinetic probe, $13.4 \mathrm{~mm}$. Tests were conducted with small diameter probes (IKPA) and the penetration ratio for a probe loaded with sand was found to be less than $20 \%$ for $10 \mu \mathrm{m}$ AED particles at $14 \mathrm{~m} / \mathrm{s}$. This clearly indicates that a rake of isokinetic probes would not be suitable for sampling in the salt environment at the WIPP site.

\section{Transmission Ratios for Shrouded Probes.}

The transmission ratio can be calculated by multiplying the penetration ratio by the transmission ratio of a clean probe (Equation 2). Data for clean shrouded probes over a range of particle sizes and free stream velocities were evaluated in an earlier study by Chandra et al. (1993).

Figure 9 shows the variation of calculated transmission ratios of a clean shrouded probe, SPRC (loading lighter than that observed in the field) and SPRA (similar loading to that observed in the field) as functions of particle size. A single point is shown for the heavily loaded probe, SPRB. For this plot, the free stream velocity is $14 \mathrm{~m} / \mathrm{s}$ and the sampling flow rate is $6-\mathrm{cfm}$. It may be noted the transmission ratios for SPRA are $0.82,0.91$ and 0.75 for particle sizes of 5,10 and $15 \mu \mathrm{m} \mathrm{AED,} \mathrm{respectively.}$

\section{Shrouded Probe with Blockage at the Flow Waistline.}

Figure 10 shows the velocity profiles in the shroud, at a distance of $51 \mathrm{~mm}$ downstream from the shroud entrance, for a clean probe and a probe having simulated non-symmetric blockage (area reduction by $33 \%$ ) at the waistline (Figure 4). It is evident that the blockage reduces the velocity inside the shroud from approximately $6 \mathrm{~m} / \mathrm{s}$ to about $4 \mathrm{~m} / \mathrm{s}$. It is important to note that the axial velocity profile with blockage is uniform, which shows the non-symmetry in the blockage does not effect the axial velocity profile. 


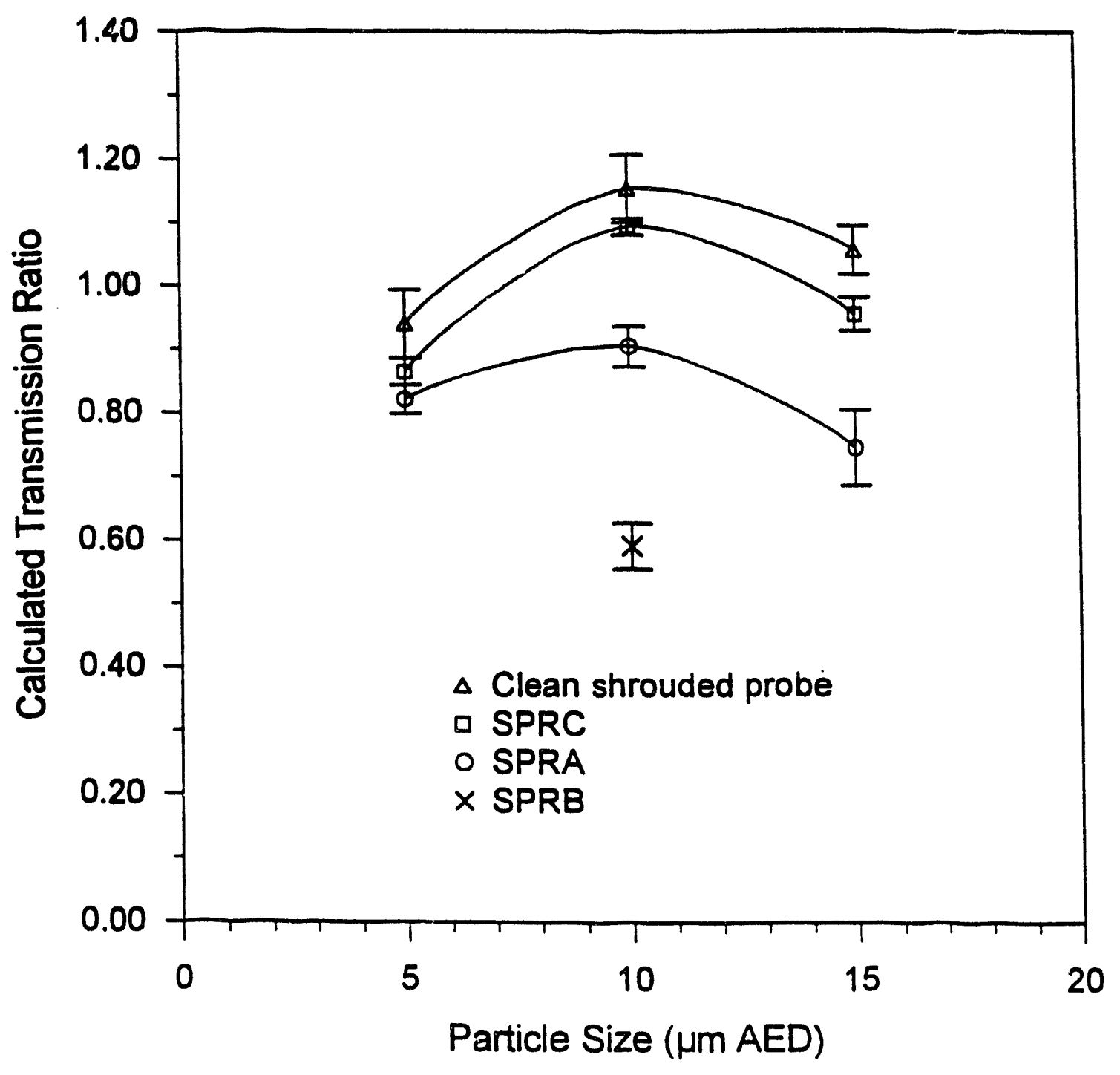

Figure 9. Transmission ratios as a function of particle size. Free stream velocity $=14 \mathrm{~m} / \mathrm{s}$. Error bands represent \pm one standard deviation. 


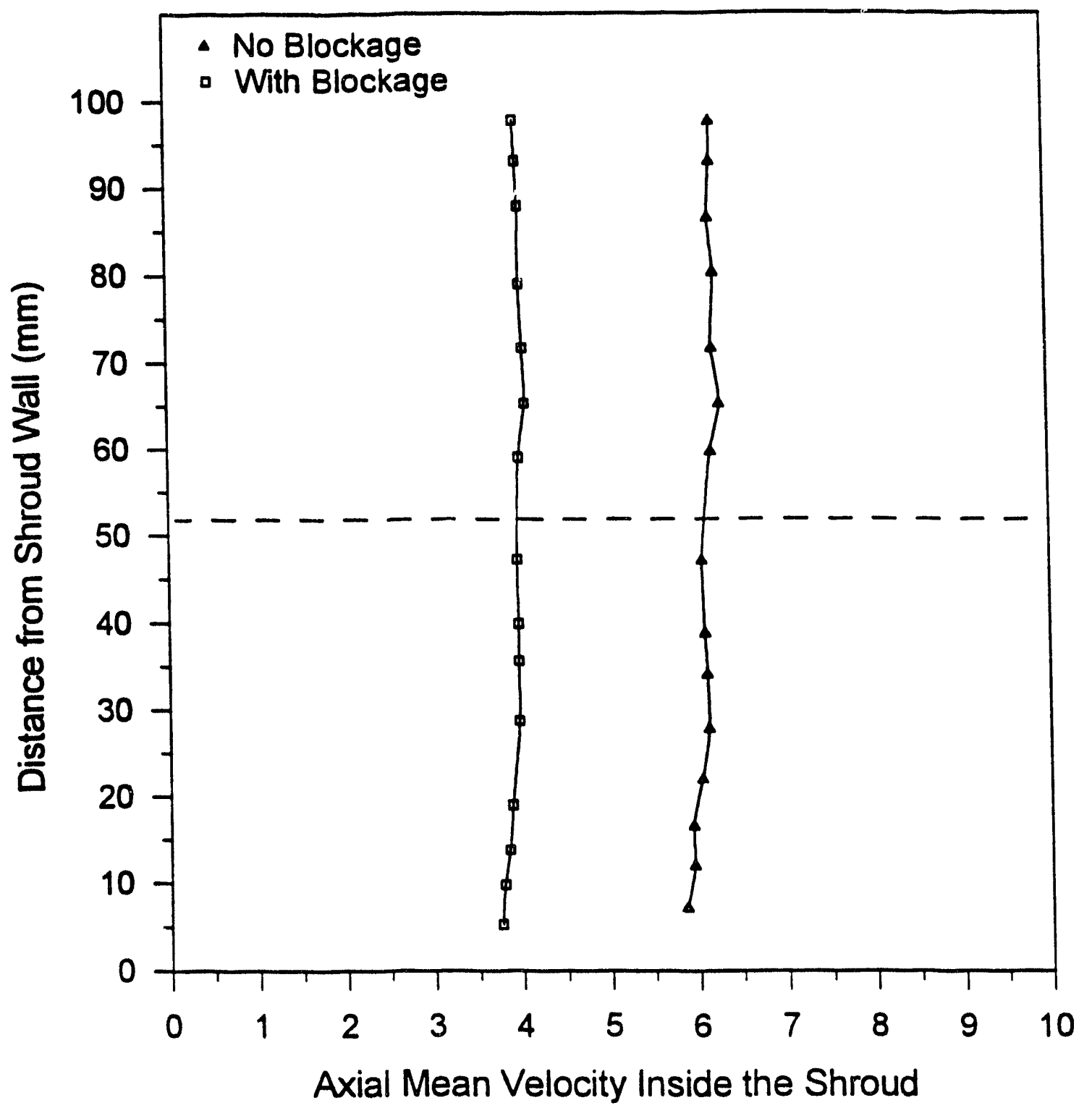

Figure 10. Axial velocity profiles in shroud with and without blockage. Traverse was made $51 \mathrm{~mm}$ downstream from shroud entrance.

Free stream velocity $=21 \mathrm{~m} / \mathrm{s}$. 
The effect of the blockage is not propagated to the sampling performance of the shrouded probe. Wind tunnel experiments with $10 \mu \mathrm{m}$ AED aerosol narticles at a wind speed of $14 \mathrm{~m} / \mathrm{s}$ showed the penetration ratio of the unit with blockage was 0.99 .

\section{Numerical Results.}

Numerically determined penetration ratios and comparative experimental results for loaded probes are given in Table 2. The numerical values of penetration ratio are based on the calculated transmission ratio of a loaded probe divided by the calculated transmission ratio of a clean probe. It may be noted that over the range of conditions for which calculations were performed, there is good agreement with experiment. For SPRA, at a particle size of $10 \mu \mathrm{m}$ AED and a free stream velocity of $14 \mathrm{~m} / \mathrm{s}$, the numerical value of the per.tration ratio is $0.8^{\text {? }}$ while that determined experimentally is 0.79 . The maximum deviation of numerical and experimental results occurred for the case of the heavily loaded unit (SPRB) where there is a $12 \%$ relative error between experimental and numerical results.

We eximined the effect of blockage in the probe entrance region by reducing the area of a clean shrouded probe by $35 \%$. The calculated penetration ratio was reduced from 1.0 to 0.94 . We then reduced the waistline area by $33 \%$ and calculated that effect on the penetration ratio. The numerical results show that the blockage in the waistline region alone has an insignificant effect on the penetration ratio. The calculated penetration ratio changes from 0.94 to 0.95 .

\section{SUMMARY AND CONCLUSIONS}

The WIPP shrouded probes at Station A are subjected to buildup of salt which can change the critical dimensions of the probes. A shrouded probe that had a buildup of particulate matter from $2 \frac{1}{2}$ years of operation at WITP site was found to have a probe inlet area that was $69 \%$ of the original area ( $2.5 \mathrm{~mm}$ buildup) and the waistline gap was reduced to $7.6 \mathrm{~mm}$ from the original value of $8.2 \mathrm{~mm}$. This salt buildup was simulated on a probe by using sand deposits (SPRA). When SPRA was tested in wind tunnels with $10 \mu \mathrm{m}$ AED aerosol particles, the 
Table 2. Comparison of computational and experimental penetration ratios. Free stream velocity $=14 \mathrm{~m} / \mathrm{s}$. Sampling flow rate $=6 \mathrm{cfm}$.

\begin{tabular}{lcccc}
\hline $\begin{array}{c}\text { Probe } \\
\text { Description }\end{array}$ & $\begin{array}{c}\text { Particle } \\
\text { Size } \\
\mu \mathrm{m} \text { AED }\end{array}$ & $\begin{array}{c}\text { Experimental } \\
\text { Penetration } \\
\text { Ratio }\end{array}$ & $\begin{array}{c}\text { Numerical } \\
\text { Penetration } \\
\text { Ratio }\end{array}$ & $\begin{array}{c}\text { Difference } \\
\text { Relative to } \\
\text { Experiment, \% }\end{array}$ \\
\hline SPRA & 5 & 0.87 & 0.78 & 10 \\
& 10 & 0.79 & 0.81 & 3 \\
& 15 & 0.71 & 0.76 & 7 \\
SPRB & 10 & 0.51 & 0.57 & 12 \\
$\begin{array}{l}\text { 35\% symmetric area reduction at } \\
\text { probe entrance }\end{array}$ & 10 & 0.90 & 0.94 & 5 \\
$\begin{array}{l}\text { 35\% symmetric area reduction at } \\
\text { probe entrance with 33\% } \\
\text { symmetric blockage at waistline }\end{array}$ & 10 & $\begin{array}{l}\text { Not relevant } \\
\text { because of } \\
\text { asymmetry }\end{array}$ & 0.95 & \\
\hline
\end{tabular}

penetration ratios were 0.79 ai $2 \mathrm{~m} / \mathrm{s}, 0.78$ at $14 \mathrm{~m} / \mathrm{s}$ and 0.72 at $21 \mathrm{~m} / \mathrm{s}$. However, the actual thansmission ratios are $0.71,0.91$ and 0.93 for the free stream velocities of 2,14 and $21 \mathrm{~m} / \mathrm{s}$, respectively. In this context it may be mentioned that transmission ratios of the clean probe for these three free stream velocities are $0.89,1.16$ and 1.30 respectively.

Wind tunnel experiments were carried out with a shrouded probe that had a lighter loading than that observed in the field units (SPRC). For such a probe, the inner probe inlet area was reduced to $87 \%$ ( $1.0 \mathrm{~mm}$ buildup) and the waistline flow passage had less than $0.5 \mathrm{~mm}$ buildup. The penetration ratio was 0.95 and the calculated transmission ratio was 1.09 for a free stream velocity of $14 \mathrm{~m} / \mathrm{s}$ and a particle size of $10 \mu \mathrm{m}$ AED.

A shrouded probe with a heavier loading than that observed in the field was also tested in wind tunnels. For this probe (SPRB) the inlet area was reduced to $31 \%$ (5.5 mm buildup) of the original inner probe area and the waistline gap was reduced to $5.8 \mathrm{~mm}$ from an original value of $8.2 \mathrm{~mm}$. The penetration ratio for $10 \mu \mathrm{m}$ AED particles at a free stream velocity of $14 \mathrm{~m} / \mathrm{s}$ was 0.51 . The corresponding calculated transmission ratio was 0.59 . We suggest that 
a salt buildup similar to that of SPRA does not affect the sampling performance beyond acceptable limits since the transmission ratios for $10 \mu \mathrm{m}$ AED aerosol particles are above $70 \%$ for all free stream velocities. That is, a buildup of thickness of $2.5 \mathrm{~mm}$ in the inlet of the internal probe could be allowed before cleaning of a shrouded probe is required. The time span for such a buildup must be determined from actual field observations. Shrouded probes that have been used at WIPP for varying time spans should be removed from the Station A duct and the salt buildups measured in order to attempt to develop a correlation between time and particulate matter buildup.

With respect to a comparison of shrouded and isokinetic probes, the shrouded probes would collect significantly more aerosol than the isokinetic counterparts. For example, a shrouded probe with a buildup similar to that on SPRA would collect 2.2 times as much aerosol $(10 \mu \mathrm{m} \mathrm{AED} \mathrm{at} 21 \mathrm{~m} / \mathrm{s})$ as an isokinetic probe with equivalent buildup (IKPB) that samples at the rate of $6 \mathrm{cfm}$. A shrouded probe with a loading similar to that of SPRC would collect 2.7 times as much aerosol as IKPB for similar conditions. Also, a loaded isokinetic probe that operates at $1 \mathrm{cfm}$ (which is in accordance to the guidance of ANSI for a flow system such as Station A at WIPP) would collect less than $20 \%$ of $10 \mu \mathrm{m}$ AED particles at $14 \mathrm{~m} / \mathrm{s}$ as would SPRA.

The presence of reasonable levels of flow blockage in the waistline region of a shrouded probe does not adversely affect the sampling performance. When 1/3 of the area was asymmetrically blocked, the penetration ratio of was 0.99 for $10 \mu \mathrm{m} \mathrm{AED} \mathrm{aerosol} \mathrm{particles} \mathrm{at}$ a free stream velocity of $14 \mathrm{~m} / \mathrm{s}$.

Numerical modeling of the performance of the probe verified the experimental results. The maximum deviation of penetration ratio between experiment and model for SPRA was 10\%, while that for SPRB at a velocity of $14 \mathrm{~m} / \mathrm{s}$ and particle size of $10 \mu \mathrm{m}$ AED was $12 \%$. 


\section{REFERENCES}

American National Standards Institute (1969). Guide to sampling airborne radioactive materials in nuclear facilities. ANSI Standard N13.1-1969. New York: American National Standards Institute.

Berglund, R.N.; Liu, B. Y. H. (1973). Generation of monodisperse aerosol standards. Environ. Sci. Technol. 7:147-153.

Chandra, S.; Ortiz, C.A., McFarland, A.R (1993). Performance of the WIPP shrouded probe at $20 \mathrm{~m} / \mathrm{s}$. Texas A\&M University, Mechanical Engineering Department, Aerosol Technology Laboratory Report 8248/04/93/ARM.

Gong, H.; Anand, N.K.; McFarland, A.R. (1993). Numerical prediction of the performance of a shrouded probe sampling in turbulent flow. In press by Aerosol Sci. and Technol.

Hampl, V.; Niemela, R.; Shulman, S.; Bartley, D.L. (1986). Use of tracer gas technique for industrial exhaust hood efficiency evaluation - where to sample? Am. Ind. Hyg. Assoc. J. 47:281-287.

McFarland, A.R.; Ortiz, C.A.; Moore, M.E.; DeOtte, Jr., R.E.; Somasundaram, S. (1989). A Shrouded Aerosol Sampling Probe. Environ. Sci. Technol. 23:1487-1492.

Olan-Figueroa, E.; McFarland, A.R.; Ortiz, C.A. (1982). Flattening coefficients for DOP and oleic acid droplets deposited on treated glass slides. Am. Ind. Hyg. Assoc. J. 43:395399. 
Appendix A

Summary of Wind Tunnel Test Data 
Table A1. Penetration ratios and calculated transmission ratios for SPRA for different free stream velocities and particle sizes.

\begin{tabular}{cccc}
\hline $\begin{array}{c}\text { Particle } \\
\text { size }(\mu \mathrm{m})\end{array}$ & $\begin{array}{c}\text { Free stream } \\
\text { velocity }(\mathrm{m} / \mathrm{s})\end{array}$ & $\begin{array}{c}\text { Penetration } \\
\text { ratio }\end{array}$ & $\begin{array}{c}\text { Calculated } \\
\text { transmission ratio }\end{array}$ \\
\hline 5 & 2 & $0.86 \pm 0.01$ & $0.83 \pm 0.01$ \\
& 14 & $0.87 \pm 0.02$ & $0.82 \pm 0.02$ \\
& 21 & $0.85 \pm 0.00$ & $0.98 \pm 0.01$ \\
10 & 2 & $0.79 \pm 0.01$ & $0.71 \pm 0.01$ \\
& 14 & $0.78 \pm 0.03$ & $0.91 \pm 0.03$ \\
& 21 & $0.72 \pm 0.01$ & $0.93 \pm 0.02$ \\
& & & \\
15 & 2 & $0.78 \pm 0.04$ & $0.64 \pm 0.03$ \\
& 14 & $0.71 \pm 0.06$ & $0.75 \pm 0.06$ \\
& 21 & $0.64 \pm 0.04$ & $0.87 \pm 0.05$ \\
\hline
\end{tabular}


Table A2. Penetration ratios and calculated transmission ratios for different free stream velocities and different probes with particulate buildups for $10 \mu \mathrm{m}$ AED particles.

\begin{tabular}{cccc}
\hline $\begin{array}{c}\text { Name of the } \\
\text { probe }\end{array}$ & $\begin{array}{c}\text { Free stream } \\
\text { velocity }(\mathrm{m} / \mathrm{s})\end{array}$ & $\begin{array}{c}\text { Penetration } \\
\text { ratio }\end{array}$ & $\begin{array}{c}\text { Calculated } \\
\text { transmission ratio }\end{array}$ \\
\hline SPRC & 2 & $0.96 \pm 0.02$ & $0.86 \pm 0.02$ \\
& 14 & $0.95 \pm 0.01$ & $1.10 \pm 0.01$ \\
& 21 & $0.87 \pm 0.02$ & $1.13 \pm 0.03$ \\
SPRA & 2 & $0.79 \pm 0.01$ & $0.71 \pm 0.01$ \\
& 14 & $0.78 \pm 0.03$ & $0.91 \pm 0.03$ \\
& 21 & $0.72 \pm 0.01$ & $0.93 \pm 0.02$ \\
SPRB & 2 & $0.50 \pm 0.01$ & $0.44 \pm 0.01$ \\
& 14 & $0.51 \pm 0.03$ & $0.59 \pm 0.04$ \\
& 21 & $0.47 \pm 0.03$ & $0.61 \pm 0.04$ \\
IKPB & 14 & $0.38 \pm 0.02$ & \\
& 21 & $0.32 \pm 0.02$ & \\
$1 \mathrm{cfm}$ & 14 & N/A & $0.19 \pm 0.01$ \\
& & & \\
\hline
\end{tabular}


Table A3. Penetration ratios and calculated transmission ratios for different particle sizes and for different probes at a free stream velocity of $14 \mathrm{~m} / \mathrm{s}$.

\begin{tabular}{cccc}
\hline $\begin{array}{c}\text { Name of the } \\
\text { probe }\end{array}$ & $\begin{array}{c}\text { Particle size } \\
(\mu \mathrm{m})\end{array}$ & $\begin{array}{c}\text { Penetration } \\
\text { ratio }\end{array}$ & $\begin{array}{c}\text { Calculated } \\
\text { transmission ratio }\end{array}$ \\
\hline SPRC & 5 & $0.92 \pm 0.02$ & $0.87 \pm 0.02$ \\
& 10 & $0.95 \pm 0.01$ & $1.10 \pm 0.01$ \\
& 15 & $0.90 \pm 0.03$ & $0.96 \pm 0.03$ \\
SPRA & 5 & $0.87 \pm 0.02$ & $0.82 \pm 0.02$ \\
& 10 & $0.78 \pm 0.03$ & $0.91 \pm 0.03$ \\
& 15 & $0.71 \pm 0.06$ & $0.75 \pm 0.06$ \\
SPRB & 10 & & $0.59 \pm 0.04$ \\
& & $0.51 \pm 0.03$ & $0.94 \pm 0.05$ \\
Clean & 5 & 1.0 & $1.16 \pm 0.05$ \\
& 10 & 1.0 & $1.06 \pm 0.04$ \\
\hline
\end{tabular}



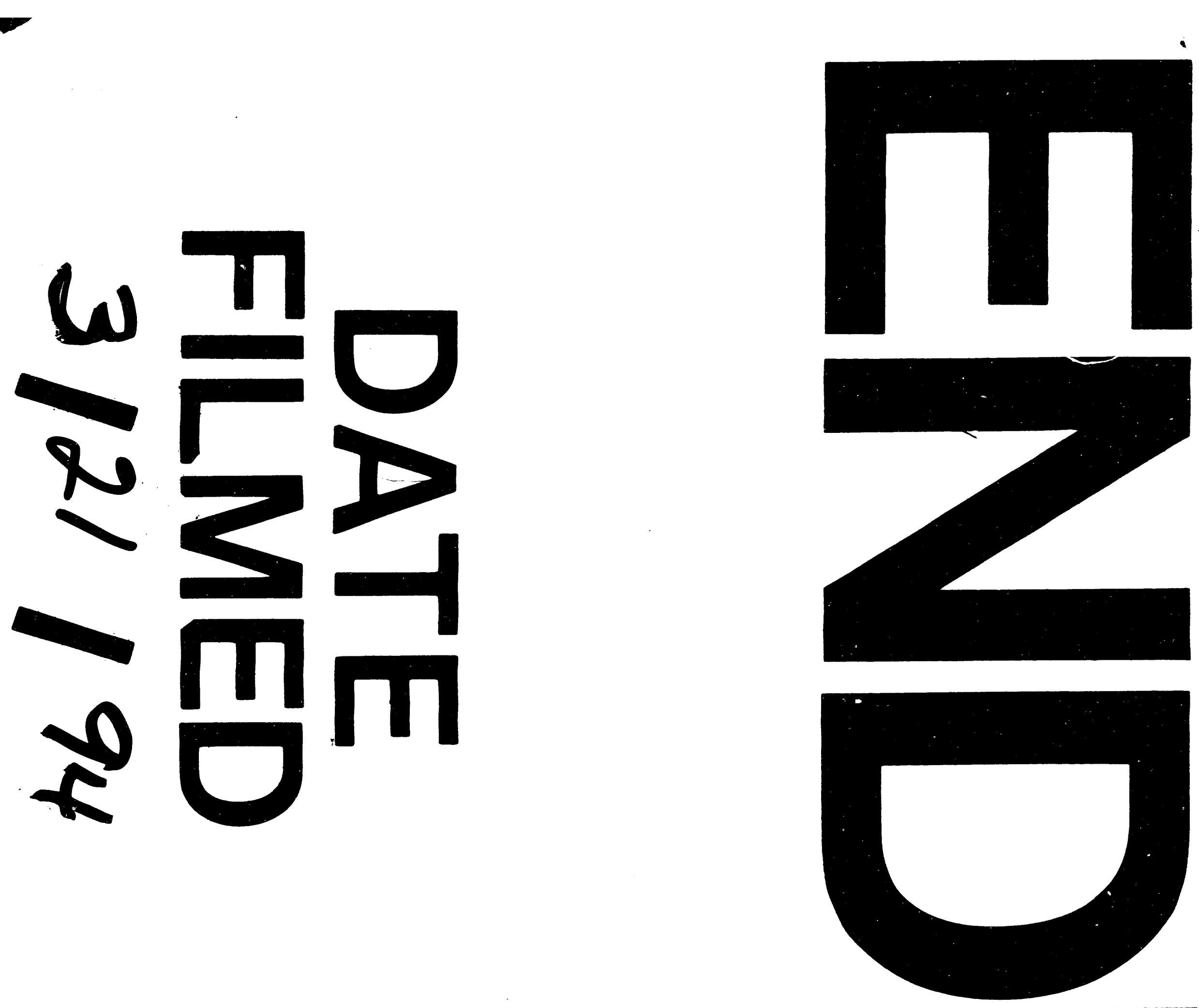
